УДК 629.7-06-533.6

\title{
Методические основы проектирования стационарных систем термостатирования ракет космического назначения на низко- и высококипящих компонентах топлива
}

\author{
C. А. Бигун \\ Государственное предприятие «Конструкторское бюро «Южное» имени М.К. Янгеля», \\ ул. Криворожская, 3, г. Днепр, 49008, Украина \\ e-mail: sbigun58@gmail.com
}

\begin{abstract}
Статья посвящена методическим принципам проектирования стационарных систем термостатирования. Изложень разновидности систем термостатирования с указанием преимуществ и недостатков. Представлены технические требования, предъявляемые к системам со стороны РКН и наземного комплекса. Указаны наиболее проблематичные из них с точки зрения реализачии в оборудовании системы. Приведен состав необходимых расчетов для проектирования стационарных систем термостатирования. Рассмотрены и проанализированы известные схемы подобных систем. В статье предложены пути создания систем, отвечающих всем предъявляемым требованиям. Следует отметить универсальность предлагаемьх методических принципов по созданию стационарных систем термостатирования для применения в составе любых известных ракетнокосмических комплексов.
\end{abstract}

Ключевые слова: Системы термостатирования; Ракеты космического назначения

\section{Методичні основи проектування стаціонарних систем термостатування ракет космічного призначення на низько- і висококиплячих компонентах палива}

\section{O. Бizyн}

Державне підприємство «Конструкторське бюро «Південне» імені М.К. Янгеля», вул. Криворізька, 3, м. Дніпро, 49008, Україна

e-mail: sbigun58@gmail.com

Стаття присвячена методичним принципам проектування стаціонарних систем термостатування. Викладені різні види і типи систем термостатування із визначенням переваг та недоліків. Подано технічні вимоги, які пред'являються до систем з боку ракет космічного призначення $і$ наземного комплексу. Вказані найбільш проблематичні з них з точки зору реалізації в обладнанні системи. Наведено необхідні розрахунки для проектування стаціонарних систем термостатування. Розглянуто і проаналізовано відомі схеми подібних систем. В статті запропоновані шляхи створення систем, які відповідають усім пред'явленим вимогам. Слід відмітити універсальність запропонованих методичних принципів зі створення стаціонарних систем термостатування для застосування в складі будь-яких відомих ракетно-космічних комплексів.

Ключові слова: Системи термостатування; Ракети космічного призначення

(C) The Author(s) 2017. This article is an open access publication

This work is licensed under the Creative Commons Attribution 4.0 International License (CC BY) http://creativecommons.org/licenses/by/4.0/

\section{1. Введение}

Системы термостатирования (СТ) стационарного типа в составе стартовых комплексов космических ракет-носителей применяются для автоматического поддержания в отсеках полезной нагрузки и в «сухих» отсеках заданного температурно-влажностного режима в оптимальном диапазоне. Термостатирование отсеков при помощи данных систем производится непрерывно в процессе предстартовой подготовки с момента доставки ракеты на пусковой стол и до момента старта.

Необходимость термостатирования продиктована применением в составе ракет двигателей, у которых максимальный удельный импульс тяги достигается, в том числе, за счет наличия определенной температуры компонентов топлива, которую необходимо обеспечивать на момент старта. Кроме этого, на борту ракет имеются космические аппараты, система управления, 
приборы и агрегаты автоматики с характерными тепловыделениями. Задача СТ состоит в создании и поддержании внутри отсеков температурно-влажностного режима, который обеспечит «комфортные» условия для старта ракеты и выполнения собственного полетного задания. Поэтому данные системы принимают непосредственное участие в подготовке и проведении пуска ракет-носителей космических аппаратов. От их нормальной работы напрямую зависят эффективность, качество и надежность ракеты, наземного комплекса и космического ракетного комплекса в целом. По этой причине наряду с другими подобными системами их относят к типу технологических, т.е. особо важных систем наземного технологического оборудования стартовых комплексов.

\section{2. Основные разновидности и типы систем термостатирования ракет космического назна- чения и требования, предъявляемые к ним}

Рассмотрим разновидности и типы систем термостатирования, наиболее применяемых в ракетно-космической технике.

По используемому рабочему давлению СТ делятся на системы низкого давления (компрессорные) и системы высокого давления (на базе газобаллонного оборудования). Существенным недостатком СТ высокого давления является большое количество баллонов, необходимость постоянной подзарядки и, как следствие, ограниченное несколькими часами время работы термостатирования. В отличие от них, СТ низкого давления имеют практически неограниченное время функционирования. Поэтому в данной статье рассмотрены именно эти системы.

Кроме разделения по рабочему давлению, СТ различают по замкнутому и разомкнутому циклам подачи продукционного воздуха.

Система замкнутого цикла построена на принципе подачи постоянного объема воздуха через отсеки ракеты. При этом указанный объем воздуха возвращается обратно в систему, которая, в данном исполнении, наиболее эффективна с точки зрения потребления энергии. Однако такая система требует наличия на борту дополнительных деталей и сборочных единиц по распределению воздуха внутри отсеков, что, в свою очередь, влечет увеличение стартовой массы ракеты и уменьшение ее грузоподъемности. Здесь также имеют место негерметичности и утечки рабочего тела, массу которого приходиться пополнять путем забора извне. В этом смысле замкнутый цикл подачи приближается к разомкнутому.

Помимо того, по признаку размещения СТ бывают транспортными и стационарными. Транспортные системы располагаются на подвижных транспортных средствах, например, железнодорожных платформах или в вагонах, автомобильных прицепах и т.д., и могут вместе с ними перемещаться. Основное оборудование стационарных СТ привязывается к строительным сооружениям и находится в них неподвижно. Хотя, в последнее время появилась концепция расположения этих систем внутри стандартных морских или оригинальных контейнеров, которые при необходимости привозятся и увозятся автомобильным транспортом.
Как правило, наибольшее применение в практике нашли стационарные СТ, которые работают по разомкнутому циклу, забирая воздух из окружающей среды. При этом воздух выступает в качестве доступного и неограниченного по количеству рабочего тела. Пройдя подготовку в оборудовании системы, термостатирующий продукционный воздух подается в подобтекательное пространство или отсек ракеты-носителя (РН) и удаляется в атмосферу.

В общем, стационарные СТ стартовых комплексов отличаются очень высокими расходами продукционного воздуха ( $\geq 23000 \mathrm{Hм}^{3} /$ час) и значительной потребляемой из сети электрической мощностью ( $\geq 2500$ кВТ).

Проектирование указанных систем начинается с выработки и анализа целого ряда технических требований. К ним относятся следующие:

- по составу системы;

- по параметрам термостатирующего продукционного воздуха;

- по стойкости к внешним воздействиям;

- по взаимодействию со смежными системами и агрегатами;

- по эргономике, обитаемости и технической эстетике;

- по эксплуатации, хранению, удобству технического обслуживания и ремонта;

- к транспортабельности;

- по безопасности и экологической защите;

- по стандартизации и унификации;

- по технологичности;

- конструктивные требования.

Кроме этого, к системе также предъявляются:

- технико-экономические требования;

- требования по метрологии, по математическому, программному и информационному обеспечению;

- требования по диагностическому оборудованию;

- требования к сырью, материалам и комплектующим изделиям;

- требования к консервации, упаковке и маркировке;

- требования по защите технологий и конфиденциальной информации;

- требования по требования к учебно-тренировочным средствам;

- требования по защите объектов права и интеллектуальной собственности;

- требования по порядку и технологии утилизации системы после истечения срока эксплуатации;

- требования по этапности разработки и срокам выполнения;

- требования по порядку выполнения и приемки этапов работы, и др.

Из всех требований, предъявляемых к СТ, основополагающими являются требования к параметрам термостатирующего продукционного воздуха и требования по стойкости к внешним воздействиям, включая климатические условия. Выполнение именно этих требований обеспечивает облик системы и, поэтому представляет собой наиболее трудоемкую часть проектирования.

Параметры термостатирующего воздуха задаются в виде определения отсеков ракеты космического назначения, подлежащих термостатированию, величин 
расходов, давлений, температур, температуры точки росы (относительной влажности) и чистоты. Климатические условия, как правило, характеризуются следующими данными:

- температурой, относительной влажностью и атмосферным давлением воздуха окружающей среды в определенном диапазоне;

- скоростью ветра на определенной высоте от поверхности земли без учета порывов и с учетом порывов;

- интегральной поверхностной плотностью потока энергии солнечного излучения;

- интенсивностью выпадения хлоридов;

- интенсивностью дождя;

- концентрацией пыли, при необходимости.

\section{3. Основная часть}

Располагая всеми техническими требованиями, предъявляемыми со стороны космического ракетного комплекса к СТ, возможно приступить к следующему шагу ее проектирования - выполнению расчетов. Перечень расчетов по СТ представлен тепловым расчетом, гидравлическим расчетом, расчетом параметров, расчетом энергетического баланса, расчетом надежности, расчетом эквивалентов нагрузки, расчетом коэффициентов ПИД-регулирования для локальных систем управления (электронагревателей воздуха, регуляторов температуры теплоносителя и другого оборудования).

Расчет тепловой производится с целью определения холодильной и тепловой мощности оборудования СТ (холодильных машин, теплообменных аппаратов, электронагревателей, адсорберов и других агрегатов). После этого выполняется тепловой расчет теплоизоляции и теплозащитного покрытия от внешних воздействий с корректировкой холодильной и тепловой мощности системы в целом.

Расчет гидравлический производится с целью определения потерь давления в гидравлических трактах в виду наличия местных сопротивлений, начиная от места забора рабочего тела (воздуха), до его выхода через узлы стыковки с горловинами термостатирования РН. Определив потери давления, предоставляется возможность правильно выбрать оборудование, предназначенное для подачи термостатирующего продукционного воздуха и режимы его работы. Настоящие расчеты должны учитывать внутреннюю геометрию всего имеющегося оборудования системы от входа до выхода рабочего тела.

Расчет параметров системы состоит в определении количественных параметров системы, заданных в техническом задании с учетом внешних воздействий и подтверждения их выполнения с учетом характеристик выбранного оборудования.

Расчет энергетического баланса выполняется с целью определения суммарной потребляемой электрической мощности всех потребителей системы.

Расчет надежности системы, как изделия ракетнокосмической техники, производится для подтверждения заданных в техническом задании требований по надежности: вероятности безотказной работы, средней наработки на отказ, среднего времени восстановления системы и др.
Расчет эквивалентов нагрузки (имитаторов сопротивления отсеков ракеты) производится с целью подтверждения правильности выбора режимов работы СТ.

Расчет коэффициентов ПИД-регулирования для локальных систем управления производится с целью подтверждения правильности выбора динамических режимов регулирования температур рабочих тел системы термостатирования.

Перечисленные расчеты должны выполняться пошагово в строго изложенной последовательности. Выполнение каждого последующего расчета невозможно без реализации предыдущего. Приведенный перечень расчетов СТ является не-обходимым и обязательным, но не полным. Дополни-тельно, в зависимости от обстоятельств и особеннос-тей разрабатываемой СТ могут выполняться: расчет на прочность, газодинамический расчет, расчет масс, цент-ров масс и моментов инерций элементов системы; рас-чет показателей стандартизации и унификации; расчет размерных цепей; расчет состава ЗИП.

В процессе проектирования СТ также одной из сложных частей работы представлен выбор оборудования по обеспечению требуемой влажности термостатирующего воздуха. Как показывает опыт разработки космических комплексов в ГП «КБ «Южное» и в других аналогичных организациях, параметры влажности термостатирующего воздуха очень сильно зависят от типа компонентов ракетного топлива.

Так, в «сухие» отсеки ракеты на высококипящих компонентах топлива (вариант 1) типа «гептил» и «амил», а также на твердых топливах, должен подаваться воздух с температурой точки росы $\left(\mathrm{t}_{\mathrm{p}}\right) 2^{\circ} \mathrm{C}$ (что соответствует $60 \%$ относительной влажности) и $4{ }^{\circ} \mathrm{C}$ (что соответствует $65 \%$ относительной влажности) для космических головных блоков. С целью реализации этого требования наиболее оптимальным выглядит применение конденсационного метода осушения воздуха, который позволяет достигать $\mathrm{t}_{\mathrm{p}}$ до $0^{\circ} \mathrm{C}$ и ниже.

А в отсеки ракет на низкокипящих компонентах топлива типа «жидкий кислород» и «керосин» (вариант 2) должен подаваться воздух с температурой точки росы минус $30{ }^{\circ} \mathrm{C}$ (что соответствует $4 \%$ относительной влажности). Для реализации этого требования наиболее оптимальным выглядит применение конденсационноадсорбционного метода осушения воздуха, который позволяет достигать $t_{p}$ до минус $70{ }^{\circ} \mathrm{C}$ и ниже, т.е. на выходе системы имеется практически сухой воздух с нулевой относительной влажностью.

На рисунке 1 по варианту 1 представлена пневмогидравлическая структурная схема стационарной СТ РН и головного блока, состоящая из промышленного кондиционера (ПКД), оборудования нагрева и очистки (ОНиО), оборудования на транспортно-установочном агрегате (ОТУА).

ПКД предназначен для предварительной очистки, нагнетания, охлаждения, осушения атмосферного воздуха, забираемого из окружающей среды, и подачи его в оборудование нагрева и очистки. ПКД состоит из нагнетателей Н1, Н2 с магистралями подвода и отвода атмосферного воздуха, подсистемы кондиционирования воздуха СКВ, теплообменника-подогревателя АТ2, регулятора температуры теплоносителя РТТ, запорной и регулирующей арматуры. В качестве нагнетателей при- 


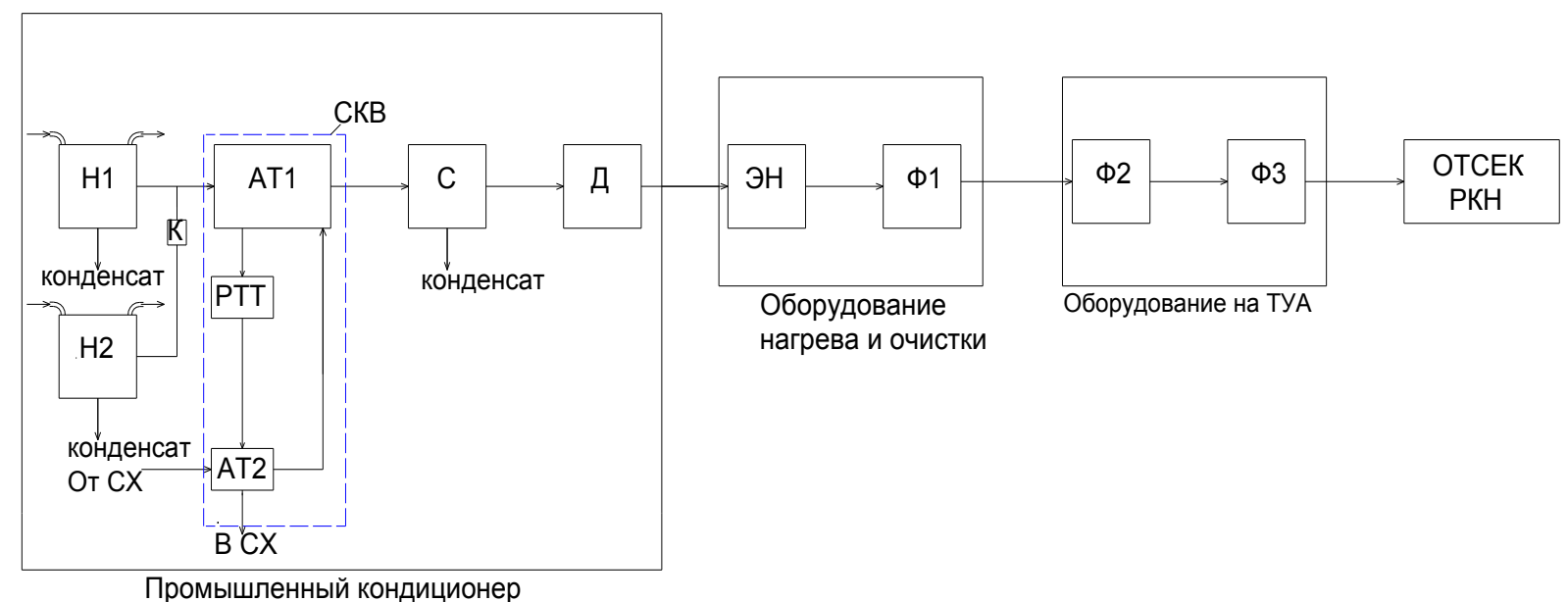

\begin{abstract}
Рисунок 1 - Пневмогидравлическая структурная схема стационарной системы термостатирования ракеты-носителя и головного блока по варианту 1: H1, H2 - компрессоры-нагнетатели; К электроклапан; AT1 - теплообменный аппарат типа «воздух-жидкость»; АТ2 - теплообменный аппарат-подогреватель типа «жидкость-жидкость»; РTT - регулятор температуры теплоносителя; CX - система холодильная; СКВ - система кондиционирования воздуха; C сепаратор конденсата-влагоотделитель; Д - подпорный дроссель; ЭН - электронагреватель; Ф1, Ф3 - фильтры тонкой очистки воздуха; Ф2 - фильтр грубой очистки воздуха.
\end{abstract}

Figure 1 - The scheme of the pneumohydraulic structural of the stationary thermal conditioning system launch-vehicle of the variant 1: H1, H2 - compressors-superchargers; $K$-electrovalve; $A T 1$ - heat exchanger of the «air-liquid»; AT2 - heat exchanger-heater of the «liquid-liquid»; PTT - coolant temperature regulator; $C X$ - refrigeration system; $C K B$ - air conditioning system; $C$ - moisture separator; $Д-$ booster choke; ЭH electric heater; $\Phi 1, \Phi 3$ - final air filters; $\Phi 2$ - primary air filter.

менены винтовые безмасляные компрессоры (КМ) с концевыми воздушными охладителями. Для обеспечения требуемой надежности один из КМ может быть резервным. Включение резервного КМ производится с помощью запорных клапанов с электрическим приводом по алгоритму системы управления подготовки и пуска для парирования нештатного режима работы. $\mathrm{CKB}$ осушает сжатый воздух до $\mathrm{t}_{\mathrm{p}}$ не выше $2{ }^{\circ} \mathrm{C}$ путем его охлаждения до $1 \ldots 3{ }^{\circ} \mathrm{C}$ в теплообменном аппарате AT1. Для охлаждения воздуха в теплообменных аппаратах используется промежуточный теплоноситель (40\% водный раствор этиленгликоля) с температурой минус $0,5{ }^{\circ} \mathrm{C}$. Данная температура поддерживается с точностью $\pm 0,5^{\circ} \mathrm{C}$ с помощью резервированного регулятора температуры промежуточного теплоносителя в соответствии с ПИД-алгоритмом. Регулирование осуществляется путем подогрева теплоносителя, поступающего от холодильной системы с температурой от минус 2 до $0{ }^{\circ} \mathrm{C}$ в АT2 за счет рекуперации тепла обратного потока, подогретого в АТ1 горячим воздухом компрессоров. Охлажденный в этих теплообменных аппаратах сжатый воздух вместе с конденсатом поступает в сепаратор конденсата ВО, где происходит отделение капельной влаги с эффективностью 99\% и последующим отводом в дренажную магистраль. После СКВ воздух поступает к подпорной диафрагме Д. Подпорные диафрагмы обеспечивают необходимое давление осушения воздуха с некоторым запасом. Далее продукционный воздух из ПКД поступает в ОНиО. Данное оборудование предназначено для доведения термостати-рующего воздуха до требуемой температуры с помощью электронагревателя ЭН, а также для его окончательной очистки до требуемого класса чистоты с помощью фильтров Ф1, Ф2, Ф3. Электронагреватели управляются внутренним регулятором температуры в соответствии с ПИДрегулятором и обеспечивают заданную температуру в диапазоне $5 \ldots .25^{\circ} \mathrm{C}$ с шагом $1^{\circ} \mathrm{C}$ на вы-ходе с точностью $\pm 2{ }^{\circ} \mathrm{C}$. После ОНиО продукционный воздух поступает в оборудование системы на транспортноустановочном агрегате. Это оборудование завершает дополнительную очистку воздуха от механических примесей и подает его к горловинам термостатируемых отсеков.

Кроме этого, на рисунке 2 по варианту 2 представлена пневмогидравлическая структурная схема стационарной СТ РН и головного блока. Схема также состоит из ПКД, ОНиО, ОТУА.

Система спроектирована на базе современного общепромышленного оборудования с элементами собственной оригинальной разработки ГП «КБ «Южное». Схема системы может состоять из независимых друг от друга линий технологического оборудования по подаче продукционного воздуха в отсеки ракеты космического назначения. Каждая из линий содержит компресcop-нагнетатель воздуха водяного охлаждения $\mathrm{H}$, аппарат теплообменный АТ, сепаратор конденсата C, адсорбер (воздухоосушитель) А, электронагреватель ЭН, фильтры грубой Ф2 и тонкой Ф1, Ф3 очистки, и магистрали подачи воздуха. Осушение воздуха в линии производится с помощью конденсационно-адсорбционного способа. Забор воздуха из окружающей среды, его подготовку, подачу к компрессорам-нагнетателям и отвод отработанного воздуха от них в окружающую среду 


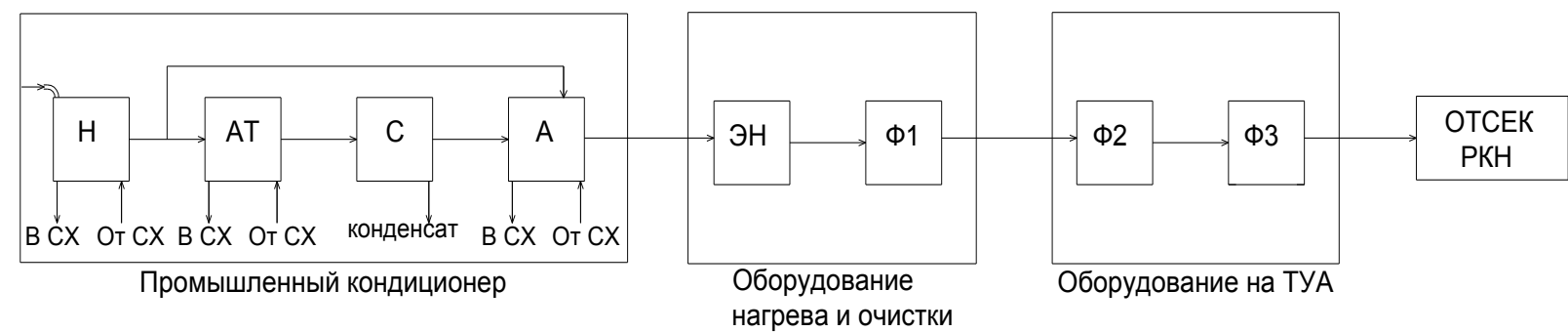

\begin{abstract}
Рисунок 2 - Пневмогидравлическая структурная схема стационарной системы термостатирования ракеть-носителя и головного блока по варианту 2: H - компрессор-нагнетатель; AT - аппарат теплообменный типа «воздух-жидкость»; $C$ - сепаратор конденсата-влагоотделитель; $A$ адсорбционный осушитель; ЭН - электронагреватель; Ф1, Ф3 - фильтры тонкой очистки воздуха; Ф2 - фильтр грубой очистки воздуха.
\end{abstract}

Figure 2 - The scheme of the pneumohydraulic structural of the stationary thermal conditioning system launchvehicle of the variant 2: $H$ - compressor-supercharger; AT - heat exchanger of the «air-liquid»; $C$ - moisture separator; $A$-adsorption dryer; $Э H$-electric heater; $\Phi 1, \Phi 3$ - final air filters; $\Phi 2$ - primary air filter.

осуществляет техническая система приточно-вытяжной вентиляции. Ее необходимость продиктована обеспечением работоспособности компрессоров, в соответствии с требованиями фирмы-производителя, путем поддержания температуры воздуха, подаваемого на вход компрессоров в диапазоне $0 \ldots 40{ }^{\circ} \mathrm{C}$, требованием предварительной очистки воздуха, а также требованием по обеспечению массового расхода воздуха для стандартных условий. Линия технологического оборудования работает следующим образом. Техническая система приточно-вытяжной вентиляции забирает воздух из окружающей среды и по специальным воздуховодам подает его с избыточным давлением до 20 Па в помещение компрессорного отделения, не допуская в нем разрежение, и с температурой $20^{\circ} \mathrm{C}$. Эта же система обеспечивает отвод отработанного воздуха в окружающую атмосферу. Попадая в компрессоры, воздух сжимается до избыточного давления 2 бар. При этом, нагревается до температуры не более $142{ }^{\circ} \mathrm{C}$. Указанный нагрев воздуха оптимален для работы теплообменников типа «воздух-жидкость» АТ, и обеспечивается с помощью жидкостного охлаждения $30 \%$ водным раствором этиленгликоля от холодильной системы с температурой, которая наиболее предпочтительна для конкретного климатического исполнения СТ. Конденсат от компрессора отводится в систему водоснабжения и канализации. Далее воздух под избыточным давлением 2 бар подается от компрессора в пластинчатый теплообменник АТ. Данные теплообменники имеют 2 секции теплообмена: холодную (жидкостную) и горячую (воздушную). Существует возможность использования отепленной жидкости для стабилизации температуры, поступающего от холодильной системы этиленгликоля с помощью ПИД-регуляторов. Секции в указанных теплообменных аппаратах работают в режиме противоточной схемы. В холодную секцию подается от холодильной системы промежуточный теплоноситель - 30\% водный раствор этиленгликоля с температурой от 6 до $8^{\circ} \mathrm{C}$, а в горячую секцию подается воздух с избыточным давлением 2 бара и температурой не более $142^{\circ} \mathrm{C}$. В результате теплообмена тепловыми потоками температура воздуха на выходе из АТ понижается до $10^{\circ} \mathrm{C}$, что соответствует $t_{p}=2^{\circ} \mathrm{C}$ при стандартных условиях с относительной влажностью воздуха $60 \%$. Конденсат, вы- деляемый из воздуха, через сепараторы циклонного типа отводится в систему водоснабжения и канализации. Для обеспечения осушения воздуха до $t_{\mathrm{p}}$ минус $30{ }^{\circ} \mathrm{C}$ при стандартных условиях с относительной влажностью 4\% после теплообменных аппаратов АТ применяются осушители водяного охлаждения $(30 \%$ водный раствор этиленгликоля с температурой от $20^{\circ} \mathrm{C}$ ) от холодильной системы. Водяные пары из сжатого воздуха удаляются методом адсорбции силикагелем, которым покрыт вращающийся барабан на стекловолокнистой основе. Для регенерации адсорбента применяется горячий воздух с температурой $142{ }^{\circ} \mathrm{C}$ от компрессора-нагнетателя. В дальнейшем воздух, после регенерации адсорбента, смешивается с основным потоком воздуха и поступает на вход в ЭН. Электронагреватели воздуха представляют собой локальную систему управления с программно-аппаратными средствами и ПИД-регулятором. Благодаря этому, температура термостатирующего продукционного воздуха доводится до необходимой с требуемой точностью и интервалами установки. После ЭН воздух проходит окончательную очистку в $Ф 1$, Ф2, Ф3 и подается в отсеки ракеты космического назначения, термостатируя последние, и через дренажные устройства удаляется в окружающую атмосферу.

\section{4. Выводы}

Таким образом, на рисунках 1 и 2 представлены схемы, позволяющие создавать стационарные СТ, отвечающие всем предъявляемым требованиям, для ракет космического назначения на низко- и высококипящих компонентах топлива.

Следует отметить универсальность предложенной методики по созданию стационарных СТ для применения в составе любых известных космических ракетных комплексов.

\section{Литература}

1. Космический ракетный комплекс «Зенит» глазами его создателей [Текст] / Под ред. В. Н. Соловьева, Г. П. Бирюкова и др. - М.: Изд-во МАИ, 2003. - 216 с.

Отримана в редакції 01.11.2017, прийнята до друку 08.12.2017 


\title{
Methodological Basis of Designing Fixed Systems of Thermostatic Control Rockets of Space Appointment on Low- and Highboiling Components of Fuel
}

\author{
S. Bigun \\ Yuzhnoie State Design Office, 3 Krivorozhskaya St, Dnepr, 49008, Ukraine \\ e-mail: sbigun58@gmail.com
}

The present article is devoted methodical principles of designing of fixed systems of thermostatic control. Variants of systems of thermostatic control with the indication of advantages and disadvantages are described. Known schemes of similar systems are considered and analysed. The technical requirements shown to systems from RSA and a land complex are presented. Most problematic of them from the point of view of realisation in the system equipment are indicated. The structure of necessary calculations for designing of fixed systems of thermostatic control is resulted. In the article ways of creation of the systems meeting the shown requirements are offered. It is necessary to note universality of the offered solution on creation of fixed systems of thermostatic control for application as a part of any known space-rocket complexes.

Keywords: Systems of Thermostatic Control; Rockets of Space Appointment

\section{References}

1. Kosmicheskii raketnyi kompleks «Zenit» glazami ego Received 01 November 2017 Approved 08 December 2017 sozdatelei (2003). Moscow, MAI, 216. 